\title{
Blueberry Floral Attributes and Their Effect on the Pollination Efficiency of an Oligolectic Bee, Osmia ribifloris Cockerell (Megachilidae: Apoidea)
}

\author{
Blair J. Sampson ${ }^{1,2}$, Stephen J. Stringer, and Donna A. Marshall \\ U.S. Department of Agriculture-Agricultural Research Service, Thad \\ Cochran Southern Horticultural Research Laboratory, P.O. Box 287, 810 \\ Highway 26 West, Poplarville, MS 39470
}

Additional index words. flower, morphology, fruit set, seed number, pollinator, Vaccinium, virgatum, ashei, corymbosum, darrowii, elliottii, myrsinites, tenellum

\begin{abstract}
We evaluated relationships between floral traits of 23 genotypes of southern blueberries and indices of pollination efficiency (fruit set, fruit abortion, seed number, and berry size) for Osmia ribifloris Cockerell, a manageable solitary bee. Flower size in Vaccinium and presumably ovary size were proportional to berry size, except for the tiny blooms of one $V$.tenellum clone ( $\mathrm{NC7808),} \mathrm{which} \mathrm{produce} \mathrm{large} \mathrm{commercial-sized} \mathrm{berries}$ of $\approx 2$ g. Longer-styled blueberry flowers visited by $O$. ribifloris produced the heaviest berries with the most seeds. Osmia ribifloris reliably pollinated 'Climax' and 'Tifblue' rabbiteye blueberries. However, the peculiarly misshapen blooms of 'Premier' rabbiteye blueberry receive less pollination from $O$. ribifloris and yield berries containing $25 \%$ fewer seeds. Fruit set for these misshapen 'Premier' flowers was equivalent to that of intact flowers indicating that this floral polymorphism would not greatly alter cultivar performance. For seven Vaccinium species, wild and cultivated alike, $80 \%$ to $100 \%$ of a plant's fruit production depends on efficient cross-pollination by bees such as $O$. ribifloris.
\end{abstract}

With recent declines in honeybee populations, manageable wild native bees could help augment natural rates of blueberry pollination (Sampson et al., 1995). However, raising enough healthy, pest-free bees for even limited release may take years. Currently in the United States, honeybees, and bumble bees to a much smaller extent, are the only available commercial pollinators of cultivated blueberries, yet a worker honeybee typically is a reluctant floral visitor because the recessed nectaries of blueberry flowers are often out of easy reach of her proboscis (Goodman and Clayton-Greene, 1988). A longer tongue provides many native bees with greater access to blueberry nectar. A wellnourished native bee will actively harvest blueberry pollen, which is linked to greater pollination efficiency, higher fruit sets, and larger berries (Sampson and Cane, 2000). Perhaps the efficiencies of honeybees and other manageable bee species can be improved by selectively breeding blueberry cultivars with bloom morphologies that complement pollinator foraging behavior (Dafni and Neal, 1997).

Selection targeting specific floral traits might give bees greater access to floral nectaries, anthers, and pistils, thereby increasing pollinator efficiency (Lyrene, 1994a). Blueberry

Received for publication 26 Sept. 2012. Accepted for publication 10 Dec. 2012.

${ }^{1}$ Research Entomologist.

${ }^{2}$ To whom reprint requests should be addressed; e-mail blair.sampson@ars.usda.gov. flowers however do not make it easy for pollinators to gather pollen and nectar rewards. In fact, pollinator visitation and pollination efficiency, particularly of honeybees, can be limited by a blueberry's long narrow flowers and poricidal anthers (Brewer and Dobson, 1969; Danka et al., 1993; Eck, 1986; Lang and Danka, 1991). These and other floral traits of course will vary as blooms age to give bees access to a flower's reproductive organs at the most opportune time. Even a modest change to flower structure can profoundly affect a bee's efficiency (Eck and Mainland, 1971; Sampson et al., 2004a). For instance, a robbery slit cut into the side of corollas by a carpenter bee effectively reduces a nectary's depth to hungry honeybees. The bees can then handle blueberry blooms more proficiently, stay longer within the crop, thereby doubling and even tripling visitation rates and pollen transfer (Sampson et al., 2004a). In addition to traits that foster bee cross-pollination, shorter styles and narrower corolla apertures may promote autogamy among self-compatible blueberry genotypes (Ritzinger and Lyrene, 1999). For commercial blueberry production, autogamy and self-compatibility may act as an insurance policy against total crop failure during acute pollinator shortages. Selfing and crosspollination in the same blueberry cultivar can produce extraordinary fruit sets of between $70 \%$ and $80 \%$ (Sampson and Spiers, 2002).

Could intense selection and inbreeding in rare instances actually produce sterile or nonfunctioning blooms? Variability in corolla shape does explain how honeybees pollinate certain rabbiteye and highbush blueberry cultivars more efficiently (Davies and Buchanan, 1979; Eck and Mainland, 1971; Goodman and Clayton-Greene, 1988; Lang and Danka, 1991; Lyrene, 1994c; Martin, 1966; Sampson and Cane, 2000). Interestingly, many cultivated blueberries express a peculiar floral trait that includes a whole array of deformities that might affect flower function and viability. One cultivar in particular, Vaccinium virgatum Aiton (syn. $V$. ashei Reade) 'Premier', often bears blooms that are to varying degrees deformed. These blooms could baffle some flower-visiting bees like oligolectic Osmia ribifloris and hence impinge on the bee's pollination efficiency (Sampson et al., 2004b). Because most blueberry plantings contain one-third or more 'Premier' bushes, growers are becoming increasingly concerned that deformed blooms on this cultivar are incapable of enticing sufficient pollinator visits for fruit set. Some farmers believe that the misshapen blooms of 'Premier' are the result of early floral bud injury inflicted by insect pests. However, these floral deformities appear to originate from a heritable trait derived from 'Ethel' ( $V$. virgatum) used in early blueberry breeding programs. If these blooms are too misshapen, bees may fail to recognize them as legitimate food sources and bypass them entirely, the consequences of which would be the setting of few if any marketable berries.

Traits of blueberry blooms, even of deformed flowers, are easily measured. These traits may be used as handy selection criteria that could help predict optimal fruit set without the need for laboriously tracking fruit set for each cultivar (Eck and Mainland, 1971; Lyrene, 1994a). Floral traits and pollen viability are heritable in Vaccinium and through selection may help improve a cultivar's rates of self-pollination, cross-pollination, or both (Ballington and Galletta, 1978; Lyrene, 1994b; Megalos and Ballington, 1987, 1988). Therefore, the objective of this study is to identify Vaccinium floral traits that promote autogamy and bee cross-pollination. The pollinator we chose to investigate is an oligolege of ericaceous plants (a blue orchard bee, Osmia ribifloris). This bee is currently under evaluation as a commercial blueberry pollinator. Although $O$. ribifloris are only indigenous to the western United Sates, their dietary host range includes plant species related to their western ericaceous host, Arctostaphylos. That is, O. ribifloris will readily adopt as suitable floral hosts several eastern species of blueberry (Sampson and Cane, 2000; Sampson et al., 1995; Stubbs et al., 1994; Torchio, 1990).

\section{Materials and Methods}

Pollinator and its management. Osmia ribifloris is a native megachilid bee that lives at higher elevations west of the Mississippi River. This species is as easily managed as other blue orchard bees like $O$. lignaria. The major difference between these bees is that $O$. ribifloris uses a narrower range of floral hosts than $O$. lignaria does. In addition to the bee's native host, manzanita, Arctostaphylos, 
cultivated highbush blueberries are excellent forage for both sexes of $O$. ribifloris. Thus, female bees have no difficulty raising broods on an exclusive diet of blueberry pollen and nectar (Sampson et al., 2004).

Our small population of $\approx 300$ Osmia ribifloris was maintained in a $9 \mathrm{~m} \times 15-\mathrm{m}$ screenhouse located at the U.S. Department of Agriculture-Agricultural Research Service Thad Cochran Southern Horticultural Research Laboratory, Poplarville, MS. We broke dormancy for $O$. ribifloris by incubating cocooned adults for up to $25 \mathrm{~d}$ at $21{ }^{\circ} \mathrm{C}$ beginning $21 \mathrm{Feb}$. 2001. These $O$. ribifloris were descendants of bees collected during the 1994-98 seasons from Austin, TX, Catalina Mountains near Tucson, AZ, Calaveras County, CA, and the San Rafael Desert, UT. Fifty-four mated female bees were released on potted blueberry bushes at a density roughly equivalent to a field stocking rate of $\approx 2000$ females per hectare of blueberry field. Females nested in paper straws $(0.7 \mathrm{~cm}$ diameter $\times 15.0 \mathrm{~cm}$ long) embedded in a linear array of 17 acrylic-coated pine blocks. Osmia ribifloris nesting was further encouraged by placing extra blocks at each corner of the screenhouse and scattering the bee's favorite leaf sources: potted roses and oak seedlings.

Blueberry host plants and experimental design. Because anthesis for the seven species and hybrids of blueberries $(\mathrm{n}=34$ clones) had to coincide with the 28-d nesting period of our Osmia, we chilled plants at $4{ }^{\circ} \mathrm{C}$ for $7 \mathrm{~d}$ inside an illuminated cold room to synchronize budbreak for some and retard development in others. Plants once moved to the screenhouse accumulated the necessary thermal units to induce flowering. Our 300 rabbiteye blueberry plants in 11.4-L plastic pots were irrigated through an automated drip emitter system. Alternatively, southern highbush blueberry and wild clones were watered manually. Species, cultivars, and clones used to measure floral attributes included the following: 1) rabbiteye blueberry, Vaccinium virgatum, 'Climax', 'Premier', and 'Tifblue'; 2) $V$. corymbosum L. clones NC7905, NC7976, KS9601, NJ8913, NJ8808, and NJ8901; 3) $V$. darrowii Camp clones NC8406, NJ8815, NJ8807, NJ8810, and NJ 8806; 4) V. elliottii Chapm. clones MS86, NJ8801, NC7924, NJ8816, NJ8802, NJ8804, NJ8819, NJ8916, NJ8917, and NC8301; 5) V. myrsinites Lam. clone NC8406a; 6) V. tenellum Aiton clones NC7808, NC8309, NC8709, NJ8831, NJ8833, NJ8835, and NC7976a; and 7) Southern highbush blueberry $(V$. corymbosum $\times V$. darrowii) cultivars Biloxi, Pearl River, Cooper, Gulfcoast, Jubilee, and Magnolia. Only 22 blueberry cultivars and clones $(65 \%$ of genotypes) bore enough fruit for assessments of fruit set and other components of pollinator efficiency. These genotypes included 'Climax', 'Jubilee', KS9601, Magnolia, MS86, NC7905, NC7976, NC7808, NC8406, NC8709, NJ8801, NJ8804, NJ8807, NJ8810, NJ8816, NJ8901, NJ8913, NJ8916, NJ8917, NJ8901, 'Premier', and 'Tifblue'. Supplemental forage for our bees included 929 younger, non-experimental plants from 31 assorted
$V$. virgatum and southern highbush blueberry. Wild blueberry clones, arranged in five random blocks, each contained one plant from each of 16 genotypes. Three or more random plants from each $V$. virgatum cultivar were assigned to a separate group. We tracked fruiting for only the most vigorous terminal racemes on each plant. These racemes $(n=335$ racemes) produced anywhere from six to 26 flowers each. Open pollination fruit set (the percentage of flowers per raceme that set fruit) was assessed for blueberry species or hybrids by tagging 25 racemes from two or more ramets per clone. Twenty-five other racemes on the same plants were tagged and then enclosed in mesh bags to exclude bees and determine rates of autogamy.

We also assessed whether deformities in 'Premier's' floral morphology affected various components of $O$. ribifloris' pollination efficiency. Percent fruit set, fruit weight, and seed number per berry were compared for 25 racemes with normal flowers and 25 racemes with deformed flowers (see Fig. 1). 'Premier' flowers, whether deformed or not, were openly pollinated by $O$. ribifloris.

Assessment of pollination efficiency. Pollination efficiency in this study was based on five components of a blueberry plant's reproductive success. They were percent green fruit set, percent ripe fruit set, percent fruit drop (abortion), berry weight, and seed number per berry. Thirty-five d after flowers were pollinated, we measured the percentage of blooms that set green fruit on the 335 tagged racemes (fruiting clusters). Fruit abortion (percentage fruit drop) was the percentage of green berries that were set by Day 35 but failed to mature by the end of harvest. Ripe berries were harvested daily from tagged clusters from 5 May 2001 through 11 July 2001. Harvested berries were immediately frozen and later thawed for wet weight and seed number determination.

Floral morphological measurements. Twenty fully opened flowers were assessed per clone. Dimensions and reproductive parts were measured for intact normal-looking (actinomorphic) Vaccinium blooms under $10 \times$ magnification using an ocular micrometer

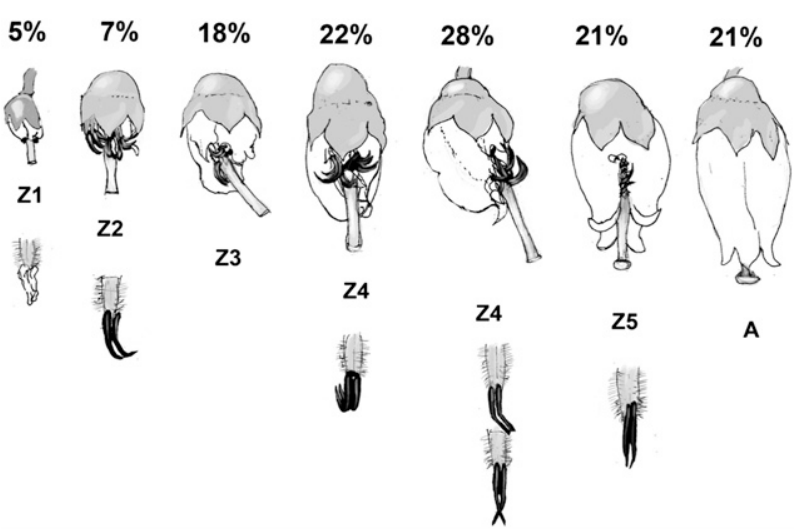

Fig. 1. Zygomorphs of field-planted 'Premier' $V$. virgatum ranked from the most deformed, Z1, to the least damaged, Z5. A normal actinomorphic bloom is shown and is labeled with an "A." Percentages of zygomorphs and actinomorphs on mature bushes are shown above (zygomorph frequency: frequency = $0.79, \mathrm{n}=384$ blooms). Stamen morphology is shown below for each respective bloom morph.
(Fig. 4). These measurements included corolla width at the widest diameter $(\mathrm{CW})$, corolla length (CL), corolla aperture width (CA), pistil length (PL), and stigma-anther pore separation (SAS) (see Fig. 4). We calculated from these measurements anther length $(\mathrm{ANTHL}=\mathrm{PL}-\mathrm{SAS})$ and stigmatic protrusion $(\mathrm{STIG}=\mathrm{PL}-\mathrm{CL})$. Pistils protruding beyond corollar apices had a positive STIG value, whereas recessed stigmas had a negative value and therefore presumably were less accessible to bees. Overall flower size (FLOSZ) was approximated using the formula for cylindrical volume: FLOSZ $\left(\mathrm{mm}^{3}\right)=$ $\pi r^{2} \mathrm{CL}$, where $r=\mathrm{CW} / 2$.

Data analyses. Because many fruiting clusters yielded no fruit, data were normalized using the $Y_{T}=(Y+0.5)^{1 / 2}$ transformation where $Y_{T}$ is the transformed percentage and $Y$ is percentage fruit set (Lyrene, 1989; Sampson and Cane, 2000). The arithmetic mean for each floral attribute per clone was paired with each independent observation of that clone's percent green and ripe fruit set, percent fruit loss, berry weight, and seed number. Multivariate analysis of covariance with harvest date as the covariate tested the effects of floral attributes (covariates), blueberry species (taxonomic effect), pollinator visitation (unrestricted visitation, no visitation), and their interactions on the pollination efficiency of the orchard bee $O$. ribifloris. Differences in floral attributes among the seven blueberry species and hybrids were verified using oneway analysis of variance. Tukey's honestly significant difference (HSD) test separated means for all analyses at $P=0.05$ level of significance (PROC GLM; SAS Institute, 1985).

\section{Results}

All five species of Vaccinium and their 34 clones including 'Premier' were self-incompatible and obligately entomophilous (Table 1; Figs. 1-3). The only unvisited blueberry blooms to develop sizeable green fruit were those of $V$. virgatum and $V$. corymbosum (Figs. 2 and 3). Nevertheless, $V$. virgatum when unpollinated lost most if not all of their berries. However, the vast majority of Vaccinium 
Table 1. Effect of Vaccinium species (SP), level of pollinator visitation (TRT: no visitation/virgin), their interaction and eight floral traits (CL...FLOSZ) on the reproductive responses of blueberries that were pollinated by Osmia ribifloris.

\begin{tabular}{|c|c|c|c|c|c|c|c|c|c|c|c|c|c|c|c|}
\hline \multirow[b]{2}{*}{ Source } & \multicolumn{3}{|c|}{ Green fruit set $(\%)$} & \multicolumn{3}{|c|}{ Ripe fruit set $(\%)$} & \multicolumn{3}{|c|}{ Fruit drop (\%) } & \multicolumn{3}{|c|}{ Fruit wt (g) } & \multicolumn{3}{|c|}{ Seeds per fruit } \\
\hline & $\mathrm{df}$ & $\mathrm{F}$ & $P$ & df & $\mathrm{F}$ & $P$ & $\mathrm{df}$ & $\mathrm{F}$ & $P$ & $\mathrm{df}$ & $\mathrm{F}$ & $P$ & $\mathrm{df}$ & $\mathrm{F}$ & $P$ \\
\hline$\overline{\mathrm{SP}}$ & 5 & 3.21 & $* \mathrm{x}$ & 5 & 2.24 & NS & $\mathrm{N} / \mathrm{A}$ & N/A & N/A & 7 & 3.56 & $*$ & 7 & 2.09 & $*$ \\
\hline TRT & 1 & 20.8 & $* * \mathrm{y}$ & 1 & 47.3 & $* *$ & 1 & 44.5 & $* *$ & 1 & 3.43 & NS & 1 & 16.6 & $* *$ \\
\hline SP*TRT & 5 & 2.63 & $*$ & 5 & 17.8 & $* *$ & N/A & N/A & N/A & N/A & N/A & N/A & N/A & N/A & $\mathrm{N} / \mathrm{A}$ \\
\hline $\mathrm{CL}$ & 1 & 0.26 & $\mathrm{NS}^{\mathrm{Z}}$ & 1 & 1.14 & NS & 1 & 1.57 & NS & 1 & 1.97 & NS & 1 & 17.1 & $* *$ \\
\hline CW & 1 & 0.03 & NS & 1 & 3.15 & NS & 1 & 0.31 & NS & 1 & 21.9 & $* *$ & 1 & 0.01 & NS \\
\hline $\mathrm{CA}$ & 1 & 0.54 & NS & 1 & 1.35 & NS & 1 & 0.04 & NS & 1 & 0.04 & NS & 1 & 2.18 & NS \\
\hline PL & 1 & 0.84 & NS & 1 & 0.48 & NS & 1 & 0.33 & NS & 1 & 34.2 & $* *$ & 1 & 8.21 & $*$ \\
\hline SAS & 1 & 0.24 & NS & 1 & 0.02 & NS & 1 & 1.20 & NS & 1 & 23.8 & $* *$ & 1 & 0.08 & NS \\
\hline STIG & 1 & 0.25 & NS & 1 & 1.09 & NS & 1 & 1.57 & NS & 1 & 2.12 & NS & 1 & 17.1 & $* *$ \\
\hline ANTHL & 1 & 0.23 & NS & 1 & 0.03 & NS & 1 & 1.20 & NS & 1 & 23.8 & $* *$ & 1 & 0.08 & NS \\
\hline FLOSZ & 1 & 0.13 & NS & 1 & 2.24 & NS & 1 & 0.16 & NS & 1 & 16.1 & $* *$ & 1 & 0.11 & NS \\
\hline Error df & 304 & & & 313 & & & 110 & & & 755 & & & 755 & & \\
\hline
\end{tabular}

${ }^{\mathrm{z}} \mathrm{N} / \mathrm{A}=$ fruit unavailable as a result of total self-incompatibility for most unvisited "bagged" flowers.

$\mathrm{y} * * P \leq 0.0001$.

x*0.0001 $<P \leq 0.05$.

STIG = stigmatic protrusion, ANTHL = anther length, FLOSZ = approximate flower size; CL = corolla length; CW = corolla width; CA = corolla aperture diameter; PL = pistil length; SAS = stigma-anther separation.

NS $=$ Nonsignificant at $P>0.05$.

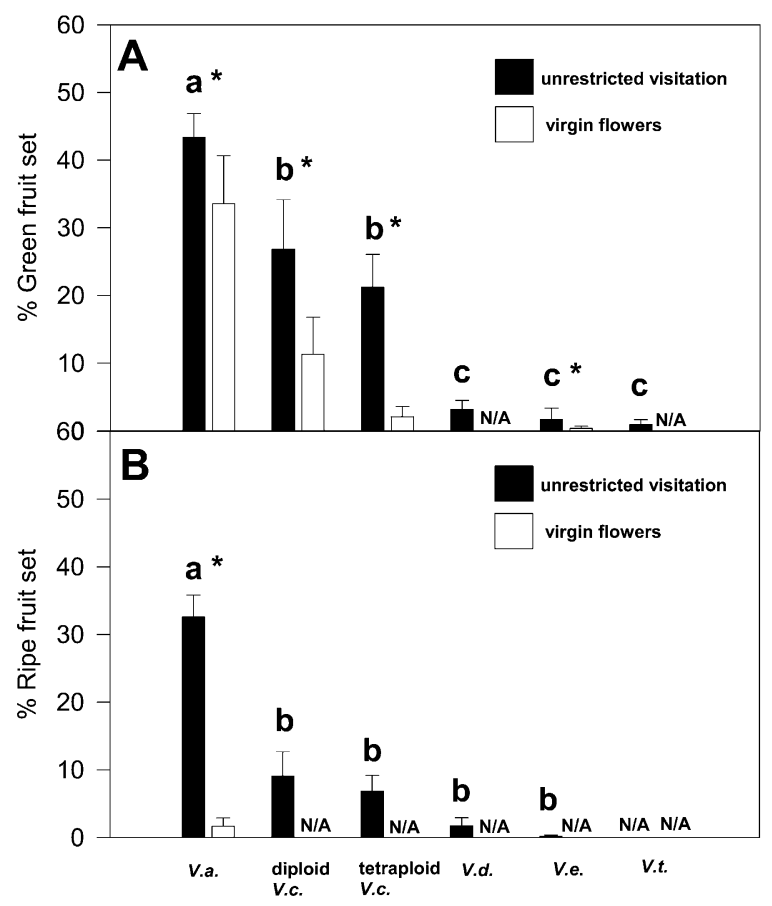

Fig. 2. Effect of pollinator visitation on (A) percent green fruit set and (B) percent ripe fruit set for five species of potted Vaccinium that grew inside the screenhouse. Bars represent means \pm 1 sE. Filled bars are fruit set values resulting from openly pollinated blossoms (unrestricted visitation). White bars show fruit set resulting from virgin flowers. The first letters in each pair denote differences in overall fruit set among the five Vaccinium species and hybrids according to Tukey's honestly significant difference at $P=0.05$. An asterisk in a pair denotes statistical differences in fruit set resulting from the level of pollinator visitation for each species $(P \leq 0.05)$. N/A signifies no fruit developed or fruit set $=0 \% . V . a .=V$. ashei (syn. $V$. virgatum $; V . c .=V$. corymbosum; $V . d .=V$. darrowi; $V$. e. $=V$. elliottii; $V . t .=V$. tenellum.

virgatum blooms visited by $O$. ribifloris yielded grade-quality fruit (Table 1; Fig. 3). Mean overall green fruit set was $43.3 \%$ and ripe fruit set was $33.6 \%$ (Table 1; Fig. 2). A loss of $10 \%$ points in fruit set during ripening is quite normal for openly pollinated $V$. virgatum. Fruit growth continued for $V$. virgatum and $V$. corymbosum for at least 35 d (Table 1; Fig. 2A), even for unvisited flowers. However, some time after sampling, fruit abortion increased for unpollinated flowers. A high percentage of rabbiteye blueberry flowers that had received no Osmia visits did set pea-sized green fruits, many of which (94\%) aborted after $35 \mathrm{~d}$ post-pollination. Deprived of Osmia pollination, only four of the 'Climax' $V$. virgatum flowers managed to set late-maturing BB-sized parthenocarpic (seedless) berries (Table 1; Fig. 3). Those 'Climax' flowers openly pollinated by Osmia set $59.1 \% \pm 8.3 \%$ green fruit and $44.5 \% \pm 7.3 \%$ of all flowers ultimately yielded a ripe fruit (percent fruit drop = $21.5 \% \pm 5.7 \%$ ). 'Tifblue' flowers yielded proportionally more green fruit and ripe fruit than had other $V$. virgatumi varieties: $69.6 \% \pm 7.4 \%$ and $55.6 \% \pm 8.2 \%$, respectively (percentage fruit drop $=18.7 \% \pm 7.9 \%$ ).

Osmia ribifloris did not pollinate 'Premier' flowers with the same efficiency as they did 'Climax' and 'Tifblue' flowers despite the comparable percentage fruit loss for pollinated flowers for all three $V$. virgatum cultivars (Tukey's HSD, $P<0.05$ ). Gross imperfections in many 'Premier' blooms affected pollination efficiency of $O$. ribifloris. Normal actinomorphic flowers set and retained more green fruit $(46.3 \% \pm 5.2 \%)$ after $35 \mathrm{~d}$ than did zygomorphs (Fig. 1; $19.2 \% \pm 3.9 \%, \mathrm{~F}=19.15$, df $=1,49, P=$ $0.0001)$. Later, however, at harvest, both floral morphs had an equal probability of producing a ripe fruit $(\mathrm{F}=1.76, \mathrm{df}=1,49, P=$ 0.1906). Clearly, fruit abortion occurred later (greater than $35 \mathrm{~d}$ ) for actinomorphs $(43.9 \% \pm 8.0 \%$ loss vs. $6.0 \% \pm 3.7 \%$ loss for zygomorphs, $\mathrm{F}=20.00$, df $=1,44, P=$ $0.0001)$. Berries produced by both forms of 'Premier' flowers weighed on average $1.84 \mathrm{~g}$ $(\mathrm{F}=0.29, \mathrm{df}=1,206, P=0.5931)$. Proportionally more berries from zygomorphic flowers were parthenocarpic (seedless) or on average contained $25 \%$ fewer seeds when compared with fruit from normal actinomorph blooms (41 seeds per berry).

Flowers of the wild blueberries, $V$. darrowii, V. elliottii, and $V$. tenellum, experienced low fruit sets (Table 1; Figs. 2 and 3). Vaccinium virgatum and unbagged clones of $V$. tenellum produced unexpectedly large fruits (Table 1; Fig. 3). Not all blueberries shared the same reproductive response to Osmia visitation. Interaction between blueberry species (notably $V$. virgatum and diploid $V$. corymbosum) and pollinator visitation levels reveal some unpollinated Vaccinium can initially set green fruit, but they ultimately abort berries before ripening.

Cultivated rabbiteye blueberries and southern highbush blueberries produced the most voluminous flowers of the seven species and hybrids examined (Table 2). In all seven 
blueberry species and hybrids, a gap (1.08 to $2.84 \mathrm{~mm}$ ) separated anthers from stigmas. Stigmas of mature flowers protruded beyond the corolla apex for all species except for $V$. elliottii (Table 2). Despite some floral variation, the eight floral features had no clear relationship to percent fruit set for the Vaccinium taxa examined (Table 1). Five floral traits (CW, PL, SAS, ANTHL, and FLOSZ) can serve as predictors of fruit weight. Berry weight, flower size, and other floral parameters often coincreased (Table 1), except in diploid $V$. tenellum (Table 1). $V$. tenellum was remarkable for producing commercial-sized fruit of $\approx 2 \mathrm{~g}$ each, well out of proportion with the mother plant's tiny blooms. Although flower size no doubt importantly determines blueberry quality, the efficiency of bees to pollinate blooms depends on to how far stigmas protrude above corolla apertures (Tables 1 and 2; Figs. 2 and 3 ).

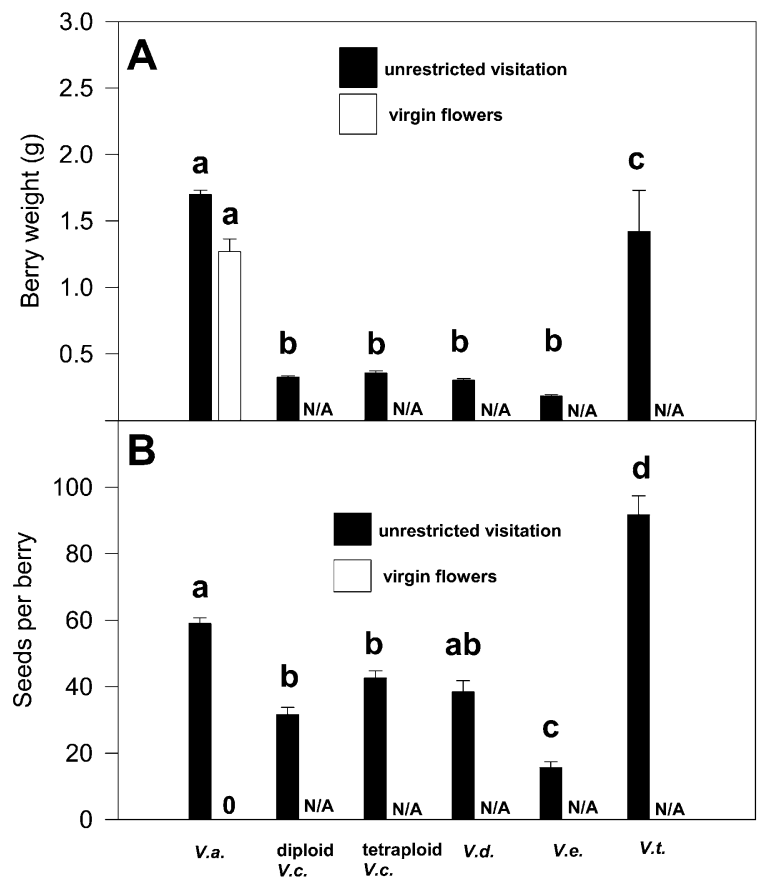

Fig. 3. Effect of pollinator visitation on (A) berry weight and (B) seeds per berry for the five species of Vaccinium used for fruit set determination. Bars represent means \pm 1 SE. Filled bars are values resulting from open-pollinated flowers (unrestricted visitation). White bars show values for virgin flowers. Letters over each bar that are different denote means that are significantly different Tukey's honestly significant difference with $P \leq 0.05$. N/A signifies no fruit were available for dissection. The " 0 " shows that only parthenocarpic "seedless" berries matured from unvisited (virgin) $V$. ashei blooms. $V$. $V . a .=V$. ashei $(\operatorname{syn} . V$. virgatum $) ; V . c .=V$. corymbosum; $V . d .=V$. darrowi; $V . e .=V$. elliottii $; . t .=$ $V$. tenellum. Note: Fruit from $V$. tenellum were picked from untagged clusters.
As mentioned before, seed number for Vaccinium fruit tends to increase as pistils protrude (STIG) farther beyond corolla apices (Table 1; Fig. 4A). Stigma position in blueberries ranged from $-2 \mathrm{~mm}$ to $+2 \mathrm{~mm}$ relative to the corolla rim. Positive values were linked to higher seed sets (Fig. 4B) in cultivated species (Fig. 4C). There was no doubt a small taxonomic effect resulted from a species' variability in pollen fertility and in the maximum number available ovules per ovary, yet corolla length, stigmatic protrusion, and the intensity of pollinator visitation were the greatest sources of variation in seed number among our seven Vaccinium species and hybrids (Table 1; Figs. 4A and 4C). Generally, for each 1-mm incremental increase in pistil length, average blueberry fruit produces an additional six seeds and gains another $0.3 \mathrm{~g}$ in mass.

\section{Discussion}

The higher pollination efficiency of $O$. ribifloris on cultivated blueberries makes this bee a prime alternative non-Apis pollinator. Although other wild Vaccinium species are suitable forage for the bee, this bee did not affect pollination very well. Perhaps the wild blueberry clones, and not the bees, were inherently poor performers. Three major $V$. virgatum cultivars set the most fruit of the 34 varieties and clones tested. However, pollination efficiency for $O$. ribifloris varied among the $V$. virgatum cultivars, primarily because one variety, 'Premier', had deformed polymorphic blooms with twisted cleft corollas and misshapen pistils and anthers. Bees had difficulty landing on or avoided altogether these misshapen flowers. Both normallooking and deformed 'Premier' blooms set market-sized fruit weighing an average of $1.8 \mathrm{~g}$. Interestingly, higher rates of seed and fruit abortion for deformed zygomorphic blooms indicate $O$. ribifloris has difficulty pollinating 'Premier' (Dafni and Neal, 1997; Stebbins, 1970). Overall, Vaccinium virgatum

Table 2. Floral morphological attributes for seven species of blueberries including five hybrid clones of southern highbush blueberry. ${ }^{\mathrm{z}}$

\begin{tabular}{|c|c|c|c|c|c|c|c|c|c|}
\hline Vaccinium species & No. clones & $\mathrm{CL}(\mathrm{mm})$ & $\mathrm{CW}(\mathrm{mm})$ & $\mathrm{CA}(\mathrm{mm})$ & PL (mm) & SAS (mm) & STIG (mm) & ANTHL (mm) & FLOSZ $\left(\mathrm{mm}^{3}\right)$ \\
\hline V. virgatum & 3 & $8.36 \pm 0.49^{y}$ & $7.28 \pm 0.52$ & $2.89 \pm 0.38$ & $10.33 \pm 0.35$ & $2.84 \pm 0.75$ & $1.96 \pm 0.45$ & $7.48 \pm 0.80$ & $349 \pm 47$ \\
\hline $\begin{array}{l}\text { V. corymbosum } \\
\times V \text {. darrowi } \\
{[\mathrm{c}]}\end{array}$ & 5 & $\begin{array}{c}8.24 \pm 1.33 \\
\mathrm{a}\end{array}$ & $\begin{array}{c}8.17 \pm 0.68 \\
b\end{array}$ & $\begin{array}{c}3.81 \pm 0.50 \\
b\end{array}$ & $\begin{array}{c}9.45 \pm 1.00 \\
b\end{array}$ & $\begin{array}{c}1.95 \pm 0.50 \\
b\end{array}$ & $\begin{array}{c}1.21 \pm 1.15 \\
b\end{array}$ & $\begin{array}{c}7.49 \pm 0.88 \\
\mathrm{a}\end{array}$ & $\begin{array}{c}431 \pm 82 \\
b\end{array}$ \\
\hline $\begin{array}{l}\text { V. corymbosum } \\
{[\mathrm{w}]}\end{array}$ & 5 & $\begin{array}{c}5.29 \pm 0.65 \\
b\end{array}$ & $\begin{array}{c}4.38 \pm 0.51 \\
\mathrm{c}\end{array}$ & $\begin{array}{c}2.08 \pm 0.38 \\
\mathrm{c}\end{array}$ & $\begin{array}{c}6.29 \pm 1.13 \\
c\end{array}$ & $\begin{array}{c}1.16 \pm 0.66 \\
\mathrm{c}\end{array}$ & $\begin{array}{c}0.99 \pm 0.77 \\
b\end{array}$ & $\begin{array}{c}5.13 \pm 0.79 \\
b\end{array}$ & $\begin{array}{c}82 \pm 27 \\
c\end{array}$ \\
\hline $\begin{array}{l}\text { V. darrowi } \\
{[\mathrm{w}]}\end{array}$ & 5 & $\begin{array}{c}5.16 \pm 1.08 \\
\mathrm{c}\end{array}$ & $\begin{array}{c}3.97 \pm 0.70 \\
\mathrm{~d}\end{array}$ & $\begin{array}{c}1.70 \pm 0.47 \\
\mathrm{~d}\end{array}$ & $\begin{array}{c}6.24 \pm 1.02 \\
c\end{array}$ & $\begin{array}{c}1.56 \pm 0.67 \\
\mathrm{~d}\end{array}$ & $\begin{array}{c}1.09 \pm 0.52 \\
b\end{array}$ & $\begin{array}{c}4.69 \pm 0.76 \\
b\end{array}$ & $\begin{array}{c}65 \pm 21 \\
d\end{array}$ \\
\hline $\begin{array}{l}V . \text { myrsinites } \\
{[\mathrm{w}]}\end{array}$ & 1 & $\begin{array}{c}4.05 \pm 0.30 \\
\mathrm{~d}\end{array}$ & $\begin{array}{c}4.44 \pm 0.24 \\
\mathrm{c}\end{array}$ & $\begin{array}{c}2.43 \pm 0.24 \\
\mathrm{e}\end{array}$ & $\begin{array}{c}5.71 \pm 0.20 \\
d\end{array}$ & $\begin{array}{c}1.33 \pm 0.27 \\
\mathrm{c}\end{array}$ & $\begin{array}{c}1.66 \pm 0.28 \\
\mathrm{a}\end{array}$ & $\begin{array}{c}4.38 \pm 0.29 \\
b\end{array}$ & $\begin{array}{c}63 \pm 7 \\
d\end{array}$ \\
\hline $\begin{array}{l}\text { V. tenellum } \\
{[\mathrm{w}]}\end{array}$ & 6 & $\begin{array}{c}5.88 \pm 0.66 \\
\mathrm{e} \\
\end{array}$ & $\begin{array}{c}3.62 \pm 0.52 \\
\mathrm{e}\end{array}$ & $\begin{array}{c}1.42 \pm 0.26 \\
\mathrm{f} \\
\end{array}$ & $\begin{array}{c}7.10 \pm 0.79 \\
\mathrm{e}\end{array}$ & $\begin{array}{c}2.15 \pm 0.48 \\
\mathrm{~b} \\
\end{array}$ & $\begin{array}{c}1.21 \pm 0.85 \\
\mathrm{~b}\end{array}$ & $\begin{array}{c}4.95 \pm 0.67 \\
b\end{array}$ & $\begin{array}{c}62 \pm 20 \\
\mathrm{~d}\end{array}$ \\
\hline
\end{tabular}

${ }^{2}$ Mean morphological measurements for $V$. corymbosum comprises both wild diploid and polyploid clones.

${ }^{\mathrm{y}}$ Mean \pm 1 SD.

${ }^{x}$ Letters that are the same within the same column indicate no interspecies difference for a specific floral trait according to Tukey's honestly significant difference test, $P \leq 0.05$.

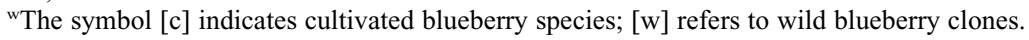

$\mathrm{CL}=$ corolla length; $\mathrm{CW}=$ corolla width $\mathrm{CA}=$ corolla aperture diameter; $\mathrm{PL}=$ pistil length; $\mathrm{SAS}=$ stigma-anther separation; $\mathrm{STIG}=$ stigmatic protrusion; ANTHL $=$ anther length; FLOSZ $=$ approximate flower size. 


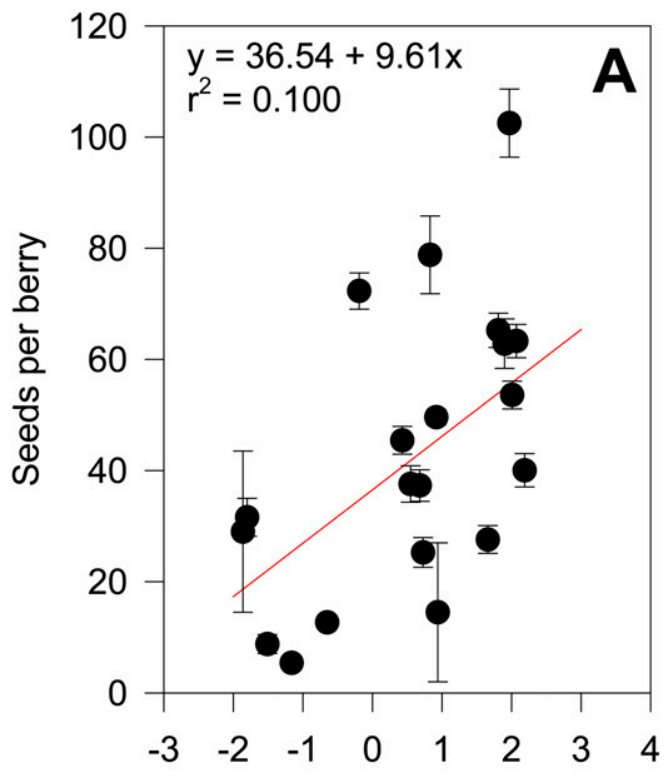

Stigmatic protrusion $(-/+\mathrm{mm})$

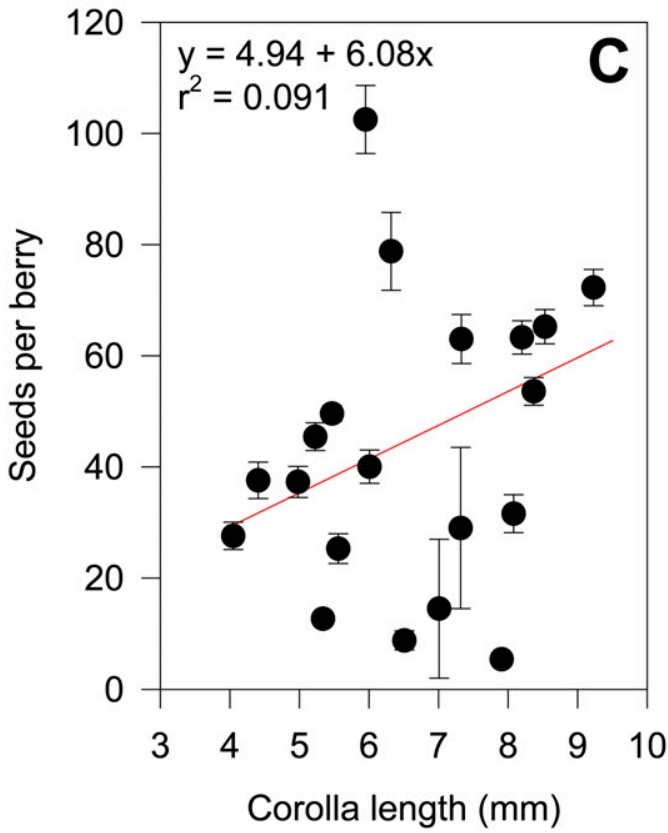

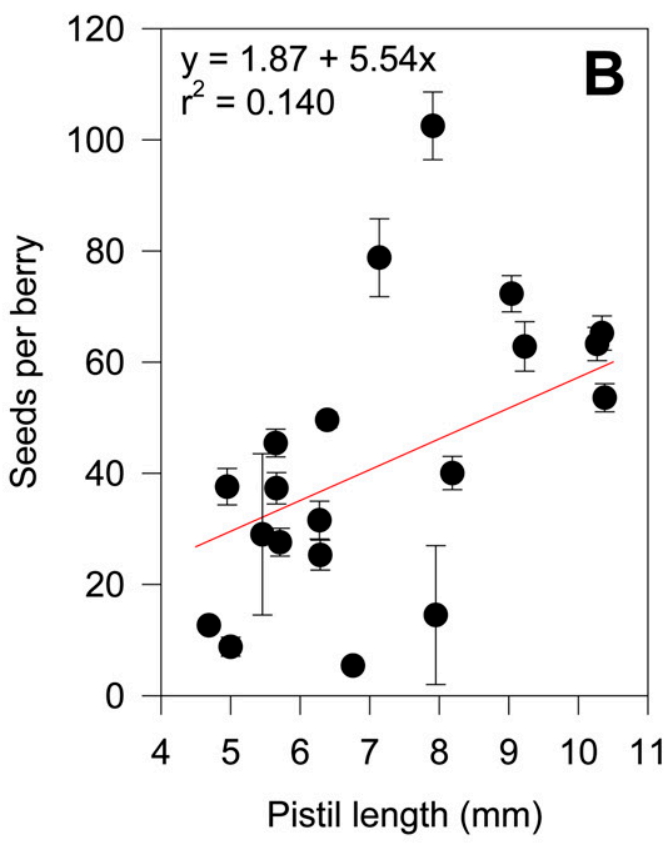

CL

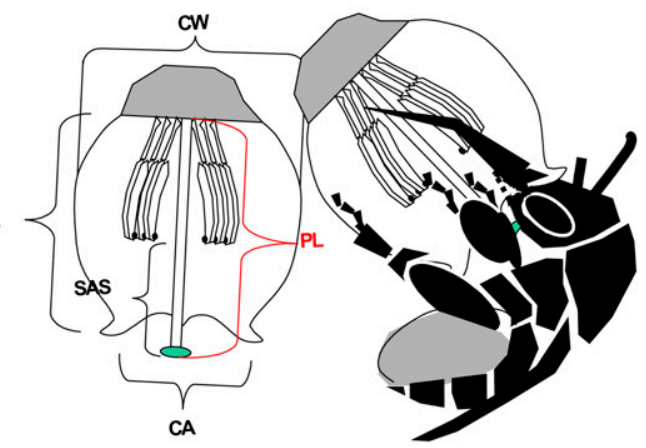

$\mathrm{CL}$ - corolla length $(\mathrm{mm})$

CW- corolla width $(\mathrm{mm})$

CA - corolla aperture ( $\mathrm{mm}$

$\mathrm{PL}$ - pistil length $(\mathrm{mm})$

SAS - stigma-anther separation $(\mathrm{mm})$

$\mathrm{PL}-\mathrm{CL}=$ stigmatic protrusion $(\mathrm{m}$

PL. SAS $=$ anther length $(\mathrm{mm})$

Fig. 4. Statistically significant linear relationships between seed number and three floral attributes for fruit resulting from $O$. ribifloris visits: (A) stigmatic protrusion, (B) pistil length, and (C) corolla length. Circles are the average number of seeds per berry \pm 1 sE for a given clone from five species of blueberry. Negative stigmatic protrusion values indicate pistils for five clones of $V$. elliottii were recessed below the corolla aperture. A regression line, equation and $r^{2}$ value are provided for each of the three plots. The inset diagram depicts the internal features of a typical blueberry flower and illustrates how floral attributes were measured and calculated. The relative position of an $O$. ribifloris female when she probes a flower is shown as a silhouette. Note how the pistil comes into contact with her lower head region.

plants solely pollinated by captive $O$. ribifloris achieved fruit sets similar to those plants pollinated the year before (Sampson and Cane, 2000) as well as open-pollinated field plots visited by a variety of native bee species (Payne et al., 1989). However, green fruit set was comparatively low inside the screenhouse, a condition that appreciably varies in commercial rabbiteye blueberry fields. Lower fruit set inside the screenhouse may have resulted from physiological stress imposed on root-bound plants grown for many years in undersized pots.
'Premier' and other cultivars of rabbiteye blueberry have among the showiest blooms of North American Vaccinium (VanderKloet, 1988). Because flower size and presumable ovary volume determine fruit size and a bee's pollination efficiency, a heftier bloom would be quite a desirable cultivar trait. A blueberry plant's field performance may benefit from even subtle heritable differences in floral shape and function that bees find highly attractive. The showy inflorescences of elite polyploid blueberries may draw in more pollinators and bear larger fruit when compared with those of their free-living diploid progenitors. Hexaploid rabbiteye blueberries are thought to have been naturally derived, in part from the hybridization between diploid rhizomatous clones of $V$. darrowii, $V$. tenellum, and crown-forming blueberry species (Ballington and Galletta, 1976). Large berry size in rabbiteye blueberry may have been inherited from certain clones of $V$. tenellum. Hybrids with other wild diploid blueberries $V$. corymbosum (75\%) and $V$. darrowii $(25 \%)$ have given rise to an entirely new class of commercial cultivars - the southern highbush 
blueberries. These polyploid blueberries tend to set the largest flowers and biggest fruit (Mulligan and Kevan, 1973). Cultivated blueberry and manzanita Arctostaphylos spp. (Ericaceae), a native desert host for $O$. ribifloris, share similar floral adaptations. Flowers are urn-shaped with elongated corollas, narrow corolla openings, and poricidal anthers, all floral features that bees can take full advantage of by specializing.

Aspects of floral morphology affected some but not all aspects of pollination efficiency for $O$. ribifloris (Eck and Mainland, 1971). Clearly, fruit set for our seven species of eastern North American Vaccinium have a strong taxonomic or phylogenetic component. Generally, however, fruit set is highest for cultivated blueberry clones. This can be expected, because cultivated plants are specifically selected for reliable fruiting within massive agricultural monocultures. However, even within the confines of a screenhouse, and among the sundry species and clones, floral morphology determines one critical aspect of crop value - berry quality, more specifically seed number, a determinant of crop earliness (Sampson and Spiers, 2002). Seed number per berry and fruit size increased for those $\mathrm{Vacci}$ nium species with long protruding pistils. Presumably, a longer pistil extending beyond the mouth of a flower increases opportunities for pollinator contact and stigmatic loading (Kearns and Inouye, 1993). Therefore, selecting varieties with squatter blooms and longer styles could profoundly increase blueberry yield at both a field and regional scale (Gorchov, 1985; Tamada et al., 1977). For decades, berries of cultivated taxa have been artificially selected for optimal size and weight. Such breeding efforts may have coincidentally increased the stylar length of blooms and perhaps inadvertently the efficiencies of attending bees.

Flowers of some blueberry species possess remarkable characteristics. Vaccinium elliottii for instance bear mature flowers with fully recessed pistils. Pollinators would therefore rarely contact stigmas of these blooms, which would result in inferior fruit sets and seed counts. However, V. elliottii is remarkable for its short gap between anthers and stigma, which by promoting selfpollination could be useful for breeding autogamous blueberry cultivars (Lyrene, 1994a; Meader and Darrow, 1944). Vaccinium tenellum was another interesting species. One clone particularly, NC7808, had the smallest flowers of the other accessions, yet produced extraordinarily large berries weighing $\approx 2.30 \pm 0.32 \mathrm{~g}$. Each of these large berries contained $103 \pm 15$ seeds. Flowers of another $V$. tenellum clone, NC 8709, were larger than those of NC7808; however, berries of the former were typically small and weighed $0.38 \pm 0.07 \mathrm{~g}$ each and contained $79 \pm 16$ seeds. This discrepancy cannot be resolved. From the data and field notes, no plants were mislabeled and fruit were carefully gathered from each potted plant. Although highly unlikely, one possible error might have been a diploid $V$. corymbosum clone grew intertwined with $\mathrm{NC} 7808$, and it is these berries and not $V$. tenellum that were harvested. However, the mean distance between the stigma and anther for NC7808 blooms was among the greatest of any other Vaccinium measured. Surely, bees would have little difficulty transferring copious pollen to its protruding pistils. The exceedingly long pistils of NC7808 could make this clone a worthy source of valuable germplasm.

It is doubtful that the greater availability of $V$. virgatum and $V$. corymbosum pollen inside the screenhouse caused a reduction in fruit set for the wild clones of $V$. elliottii, $V$. tenellum, and $V$. darrowii. Self-incompatible blueberry species and clones produced adequate seed. Actually, average seed numbers for the few berries produced by openly pollinated clones were equal to or greater than berries from other $V$. darrowii and $V$. tenellum clones (Ballington and Galletta, 1976). Some wild blueberries, although partially self-fruitful (Meader and Darrow, 1944), have blooms poorly equipped for obligate autogamy. Without pollinators, all Vaccinium species tested were effectively selfsterile, that is their flowers were physically incapable of accomplishing self- or crosspollination without some external agent first removing pollen (e.g., a bee or a scientist) (Ballington and Galletta, 1978).

As a result of the self-incompatible nature of blueberry flowers, a lack of bee pollination increased levels of fruit abortion. Berry growth was also retarded on some fruiting clusters, thereby producing diminutive "shotberries." Rabbiteye blueberry flowers may seem to set adequate fruit during the first $35 \mathrm{~d}$ post-bloom, even if unvisited; however, the ultimate fate of their developing berries depends on whether ample cross-pollination had taken place. Only $4 \%$ to $5 \%$ of $V$. virgatum fruit actually matured in the absence of any cross-pollination; these berries were small, seedless, and ripened much later. This phenomenon of delayed fruit drop could very well vex the most diligent blueberry farm managers, because their early assessment of pollination may indicate no fruit set problems, but halfway into fruit development, berries begin aborting en mass. Without first scouting fields for bee activity during bloom, farmers might erroneously blame post-zygotic factors (e.g., insect pests, drought, and disease) for nominal production, when in fact unsatisfactory pollination had occurred.

\section{Literature Cited}

Ballington, J.R. and G.J. Galletta. 1976. Potential fertility levels in four diploid Vaccinium species. J. Amer. Soc. Hort. Sci. 101:507-509.

Ballington, J.R. and G.J. Galletta. 1978. Comparative crossability of four diploid Vaccinium species. J. Amer. Soc. Hort. Sci. 103:554-560.

Brewer, J.W. and R.C. Dobson. 1969. Pollen analysis of two highbush blueberry varieties $\mathrm{Vac}$ cinium corymbosum. J. Amer. Soc. Hort. Sci. 94:251-252.

Dafni, A. and P.R. Neal. 1997. Size and shape in floral advertisement: Measurement, concepts and implications. Acta Hort. 437:121-140.
Danka, R.G., G.A. Lang, and C.L. Gupton. 1993. Honeybee (Hymenoptera: Apidae) visits and pollen source effects on fruiting of 'Gulfcoast' southern highbush blueberry. J. Econ. Entomol. 86:131-136.

Davies, F.S. and D.W. Buchanan. 1979. Fruit set and bee activity in four rabbiteye blueberry cultivars. Proc. Fla. State Hort. Soc. 92:246247.

Eck, P. 1986. Blueberry: Pollination requirements, p. 75-85. In: CRC handbook of fruit set and development. CRC Press, Inc., Boca Raton, FL.

Eck, P. and C.M. Mainland. 1971. Highbush blueberry fruit set in relation to flower morphology. HortScience 6:494-495.

Goodman, R.D. and K.A. Clayton-Greene. 1988 Honeybee pollination of highbush blueberries (Vaccinium corymbosum). Austrail. J. Exp. Agr. 28:287-290.

Gorchov, D.L. 1985. Fruit ripening asynchrony is related to variable seed number in Amelanchier and Vaccinium. Amer. J. Bot. 72:1939-1943.

Kearns, C.A. and D. Inouye. 1993. Techniques for pollination biologists. Univ. Press of Colorado, Niwot, CO.

Lang, G.A. and R.G. Danka. 1991. Honey beemediated cross- versus self-pollination of 'Sharpblue' blueberry increases fruit size and hastens ripening. J. Amer. Soc. Hort. Sci. 116: 770-773.

Lyrene, P.M. 1989. Pollen sources influences fruiting of 'Sharpblue' blueberry. J. Amer. Soc. Hort. Sci. 114:995-999.

Lyrene, P.M. 1994a. Variation within and among blueberry taxa in flower size and shape. J. Amer. Soc. Hort. Sci. 119:1039-1042.

Lyrene, P.M. 1994b. Environmental effects on blueberry flower size and shape are minor. J. Amer. Soc. Hort. Sci. 119:1043-1045.

Lyrene, P.M. 1994c. Seediness of native and improved rabbiteye blueberry. HortScience 29: 699.

Martin, E.C. 1966. Honey bee pollination of the highbush blueberry. Amer. Bee J. 106:366367.

Meader, E.M. and G.M. Darrow. 1944. Pollination of the rabbiteye blueberry and related species. Proc. Amer. Soc. Hort. Sci. 45:267-274.

Megalos, B.S. and J.R. Ballington. 1987. Pollen viability in five southeastern United States diploid species of Vaccinium. J. Amer. Soc. Hort. Sci. 112:1009-1012.

Megalos, B.S. and J.R. Ballington. 1988. Unreduced pollen frequencies versus hybrid production in diploid-tetraploid Vaccinium crosses. Euphytica 39:271-278.

Mulligan, G.A. and P.G. Kevan. 1973. Color, brightness, and other floral characteristics attracting insects to the blossoms of some Canadian weeds. Can. J. Bot. 51:1939-1952.

Payne, J.A., J.H. Cane, A.A. Amis, and P.M. Lyrene. 1989. Fruit set, seed size, seed viability and pollination of rabbiteye blueberries ( $\mathrm{Vac}$ cinium ashei Reade). Acta Hort. 241:38-43.

Ritzinger, R. and P.M. Lyrene. 1999. Flower morphology in blueberry species and hybrids. HortScience 34:130-131.

Sampson, B.J. and J.H. Cane. 2000. Pollination efficiencies of three bee (Hymenoptera: Apoidea) species visiting rabbiteye blueberry. J. Econ. Entomol. 93:1726-1731.

Sampson, B.J., J.H. Cane, and J. Neff. 1995. Blue bees for blueberries. Alabama Agricultural Experiment Station, Auburn University Highlights Agr. Res. 42:12, 13, 15.

Sampson, B.J., R.G. Danka, and S.J. Stringer. 2004a. Nectar robbery by bees Xylocopa virginica and Apis mellifera contributes to the 
pollination of rabbiteye blueberry. J. Econ. Entomol. 97:735-740.

Sampson, B.J., S.J. Stringer, J.H. Cane, and J.M. Spiers. 2004b. Screenhouse evaluations of a blue orchard bee Osmia Ribifloris (Hymenoptera: Apidae) as a supplemental pollinator for southeastern blueberries. Blueberry Research Extension North American Workers Conference Proceedings. Small Fruits Review 3:381392.

Sampson, B.J. and J.M. Spiers. 2002. Evaluating Bumblebees as pollinators of 'Misty' southern highbush blueberry growing inside plastic tunnels. Acta Hort. 574:53-61.

SAS Institute. 1985. SAS user's guide: Statistics Version 5 edition. SAS Institute Inc., Cary, NC.

Stebbins, G.L. 1970. Adaptive radiation of reproductive characteristics in angiosperms. I. Pollination mechanisms. Annu. Rev. Ecol. Syst. 1:307-326.

Stubbs, C.S., F.A. Drummond, and E.A. Osgood. 1994. Osmia ribifloris biedermannii and Megachile rotundata (Hymenoptera: Megachilidae) introduced into lowbush blueberry agroecosystems in Maine. J. Kans. Entomol. Soc. 67:173-185.

Tamada, T., H. Iwagaki, and S. Ishikawa. 1977. The pollination of rabbiteye blueberries in Tokyo. Acta Hort. 61:335-341.

Torchio, P.F. 1990. Osmia ribifloris, a native bee species developed as a commercially managed pollinator of highbush blueberry (Hymenoptera: Megachilidae). J. Kans. Entomol. Soc. 63:427-436. Vander Kloet, S. 1988. The genus Vaccinium in North America. Research Branch, Agriculture Canada. 1828:201. 